\title{
Exploring steam stability of mesoporous alumina species for improved carbon dioxide sorbent design
}

Matthew E. Potter, ${ }^{[\mathrm{a}] \varphi}$ Jason J. Lee, ${ }^{[\mathrm{a}]}$ Lalit A. Darunte, ${ }^{[\mathrm{a}]}$ Christopher W. Jones ${ }^{[\mathrm{a}] *}$

[a] Dr. M. E. Potter, J. J. Lee, Dr. L. A. Darunte and Prof. C. W. Jones: School of Chemical \& Biomolecular Engineering, Georgia Institute of Technology, 311 Ferst Drive NW, Atlanta, GA, 30332 (USA)

*E-mail: cjones@chbe.gatech.edu

$\varphi$ Present address for Matthew E. Potter: Department of Chemistry, University of Southampton, Southampton, Hants, SO17 1BJ, UK.

\begin{abstract}
$\underline{\text { Abstract }}$
Many different metrics exist to assess the efficacy of a carbon capture sorbent, though one of the pivotal characteristics is stability on regeneration, most notably steam stability, which applies to steam stripping regeneration, a technique proposed for capture of $\mathrm{CO}_{2}$ from humid flue gas. In this study the steam stability of two different mesoporous alumina species is compared, with an aim to tune the synthesis methodology, and the local structure and crystallinity of the samples, to create a stable regenerable sorbent. The roles of calcination temperature and aminopolymer impregnation on sorbent stability and structure are also investigated using a wide range of characterization techniques to specifically probe the influence of the alumina support. We show through this study that support choice, and support stability, can play an important role in sorbent design for carbon capture. We highlight that regular crystallinity (such as in $\gamma$-alumina), hinders the formation of pseudo-boehmite, retaining its $\mathrm{CO}_{2}$ uptake. Further we show that the addition of aminopolymers (PEI) can facilitate phase changes, however maintains the mesoporosity of the sample, a key metric for $\mathrm{CO}_{2}$ uptake.
\end{abstract}

\section{$\underline{\text { Keywords }}$}

Alumina, Steam-stability, $\mathrm{CO}_{2}$ capture, aminopolymer 


\section{Introduction}

One of the primary challenges of an expanding and developing global population is increasing energy demands, where fossil fuels will almost certainly be the primary contributor for the foreseeable future [1]. While finite fossil fuel reserves mean this cannot be sustained indefinitely, the immediate concern is the accompanied generation of greenhouse gases. It is widely known that increasing atmospheric $\mathrm{CO}_{2}$ concentration is linked to violent weather conditions, and adverse health effects, as such, legislation is being developed to control its emission [2,3]. This has led to a significant rise in the development of carbon capture and sequestration (CCS) techniques.

The current benchmark post-combustion CCS technology employs liquid amines (typically monoethanolamine) to curb $\mathrm{CO}_{2}$ emissions from power plants, and other industrial point sources, accounting for over $60 \%$ of global $\mathrm{CO}_{2}$ emissions [4]. While this has been widely implemented for numerous separations (though not post-combustion $\mathrm{CO}_{2}$ capture), it has several disadvantages. The highly volatile amines lead to sorbent loss and equipment corrosion. Further, significant amounts of energy are needed for regeneration, making the process costly, and less environmentally sustainable [5,6]. As such, a range of solid sorbents (e.g. with advantaged heatcapacities) have been investigated for CCS applications with zeolites [7], MOFs [8], activated carbons [9], alkali earth metals [10] and amine-based solids [11-16] among the most common. Amine-based solids have attracted significant as the combination of a porous support, with tunable amine sites, provides a robust material with strong $\mathrm{CO}_{2}-$ amine interactions. This facilitates rapid $\mathrm{CO}_{2}$ uptake, even at low $\mathrm{CO}_{2}$ concentrations (400 ppm, simulated direct air capture conditions) [3]. As a result, the many different amine-based sorbents have been grouped into four classes, based on how the amine is added to the material: an oligomeric/polymeric species impregnated within the pore (class 1) [17-20], chemically grafted within the pore via an organosilane (class 2) [21-23], polymerized in situ within the pore (class 3) [24] or a combination of separate oligomeric/polymeric and grafted organosilane species (class 4) [25]. 
Class 1 aminopolymer-impregnated materials have received a significant amount of attention as the high amine content bestows improved $\mathrm{CO}_{2}$ uptake [26-28]. Among the most widely researched amimopolymers is poly(ethyleneimine) (PEI), as its larger molecular weight makes it more resistant to leaching, compared to smaller amines [29]. The most common supports for aminopolymers are mesoporous silica and aluminas [30,31], however novel new technologies are rapidly emerging [32,33]. While the majority of literature utilizes silica supports, aluminas have repeatedly been shown to be more thermally and chemically resilient [34,35]. While many studies focus on optimizing the carbon capture properties of these class 1 materials, comparatively few focus on the practical aspects of regeneration or stability [36,37], which are vital to the regeneration process, and for industrial implementation.

Typically aminopolymer systems are regenerated using a combination of pressure, temperature or vacuum swing desorption techniques [38]. Yet recent work has shown the benefits of steam stripping as a regeneration technique $[39,40]$. Steam stripping can utilize inexpensive, low-value steam that is readily available, making it highly appealing. Direct steaming of sorbents has been shown to facilitate faster $\mathrm{CO}_{2}$ desorption, as the water disrupts the $\mathrm{CO}_{2}$-amine interactions [41]. Once the $\mathrm{CO}_{2}$ is desorbed, the steam is then condensed, leaving a stream of high purity $\mathrm{CO}_{2}$ for sequestration [42-44]. It is also noted that even if an alternative regeneration technique is used, the flue gas emitted from industrial plants, and other point sources, is not dry, containing between $3-10 \% \mathrm{H}_{2} \mathrm{O}$ [44]. Thus, regardless of the regeneration technique employed, steam stability is still fundamental to practical sorbent design. Several studies have focused on the stability of the amine species under these simulated steam stripping conditions [41-44]. We have previously shown that amine-functionalized mesocellular foam (MCF) is susceptible to structure degradation on steaming. It was shown that both surface area and pore volume of MCF-PEI greatly reduced from $201 \mathrm{~m}^{2} / \mathrm{g}$ and $1.54 \mathrm{~cm}^{3} / \mathrm{g}$ to $72 \mathrm{~m}^{2} / \mathrm{g}$ and $0.58 \mathrm{~cm}^{3} / \mathrm{g}$ after steaming in air for 24 hours [36]. This, in combination with amine loss, led the $\mathrm{CO}_{2}$ uptake to drop from 1.26 $\mathrm{mmol} / \mathrm{g}$ to $0.91 \mathrm{mmol} / \mathrm{g}$ [36]. However, Choi et al suggest that silicas with thicker walls, larger pore volumes and pore diameters could be more resilient to steam stripping. They showed that macroporous silica impregnated with PEI can retain $90 \% \mathrm{CO}_{2}$ uptake after 14 days of steaming, whereas PEI impregnated MCM-41, SBA-15 and MCF could only retain 38\%, 50 \% and 58 \% respectively [44]. Despite these studies, few have focused on the stability of the support in isolation. 
In our previous work we compared the $\mathrm{CO}_{2}$ uptake of two different class 2 mesoporous alumina supports [45]. One support was 'ordered', with a crystalline $\gamma-\mathrm{Al}_{2} \mathrm{O}_{3}$ structure, with entwinned mesoporous regions, while the other support was 'disordered' with no obvious local structure. The two bare supports had notable differences, with the 'disordered' species possessing strong basic sites, leading to greater $\mathrm{CO}_{2}$ uptake, and stronger interactions with the support ( $80 \mathrm{~kJ}$ $\mathrm{mol}^{-1}$ ). In contrast, the ordered support, behaved in a similar fashion to silica. In this study we aim to understand the stability of these two different supports under simulated steam stripping conditions. In doing so we observe the influence of calcination temperature on these supports, to optimize their physico-chemical properties for future sorbent development, using a range of characterization techniques to probe the alumina supports. We also compare the influence of impregnating the supports prior to steam stripping, thereby observing the influence of the PEI aminopolymer on structural changes resulting from steam-stripping. We believe this applied study will aid the practical development of $\mathrm{CO}_{2}$ sorbents, while also being highly relevant to other fields such as catalysis, specifically, aqueous phase reforming, where steam stability is a highly pertinent subject for alumina-supported catalysts [46,47].

\section{Materials and Methods}

\subsection{Chemicals}

All chemicals were obtained from Sigma Aldrich and used without further purification.

\subsection{Synthesis of ordered mesoporous alumina; OAl}

First, $13.80 \mathrm{~g}$ of Catapal B alumina was sonicated for $90 \mathrm{~min}$ in a solution of $200 \mathrm{~mL}$ of deionized water with $0.9 \mathrm{~mL}$ of concentrated nitric acid to give a white suspension. This was stirred at $60{ }^{\circ} \mathrm{C}$ for $18 \mathrm{~h}$. Separately, $15.54 \mathrm{~g}$ of P123 was dissolved in $200 \mathrm{~mL}$ of ethanol. This was added to the alumina suspension and stirred at room temperature for $24 \mathrm{~h}$. The sample was then synthesized by heating to $60{ }^{\circ} \mathrm{C}$ in an evaporation dish for $48 \mathrm{~h}$. The resulting yellow sample was dried overnight at $75^{\circ} \mathrm{C}$ and subsequently calcined at a ramp rate of $1{ }^{\circ} \mathrm{C} / \mathrm{min}$ to either 400 , 
550, 700 or $900{ }^{\circ} \mathrm{C}$ (as indicated) where it was held for $4 \mathrm{~h}$. This series of species is labelled as "ordered" as it is known to form $\gamma-\mathrm{Al}_{2} \mathrm{O}_{3}$, hence form in an ordered fashion [45].

\subsection{Synthesis of disordered mesoporous alumina; DAl}

First, $20.64 \mathrm{~g}$ of P123 was dissolved in $500 \mathrm{~mL}$ of ethanol. Once dissolved, $35 \mathrm{~mL}$ of concentrated nitric acid was added along with $51.15 \mathrm{~g}$ of aluminum isopropoxide. This was stirred vigorously for $5 \mathrm{~h}$ at room temperature. The solution was then synthesized by heating to $60{ }^{\circ} \mathrm{C}$ for $48 \mathrm{~h}$. The material was then calcined (without further drying) at 400, 550, 700 or 900 ${ }^{\circ} \mathrm{C}$ (as indicated) for $4 \mathrm{~h}$, with a ramp rate of $1{ }^{\circ} \mathrm{C} / \mathrm{min}$. This series is labelled as "disordered" as it is not known to be amorphous and not form a specific alumina phase [45].

\subsection{PEI Impregnation}

Initially, $1.0 \mathrm{~g}$ of mesoporous alumina was stirred with $15 \mathrm{~mL}$ of methanol at room temperature for 1 hour. A $20 \mathrm{~mL}$ solution of methanol containing either $670 \mathrm{mg}$ of $800 \mathrm{MW}$ branched poly(ethyleneimine) was added to the slurry to achieve $40 \mathrm{wt} \%$ of PEI and stirred for a further 24 hours at room temperature. The solvent was then removed under reduced vacuum at $50^{\circ} \mathrm{C}$ to yield a powder. The sample was then dried at $110^{\circ} \mathrm{C}$ for 12 hours at 10 mbar. Samples impregnated with PEI are labelled with "PEI“.

\subsection{Simulated steam stability}

Typically, $0.3 \mathrm{~g}$ of powder was placed into a Teflon holder, covered with a metal frit, designed to allow water vapor through, but not liquid water. The Teflon holder was placed into an autoclave with $20 \mathrm{~mL}$ of water, purged with nitrogen thrice, and heated to $120^{\circ} \mathrm{C}$ for $20 \mathrm{~h}$. The powder was then removed and dried under 10 mbar of vacuum at $110^{\circ} \mathrm{C}$ for $12 \mathrm{~h}$. Samples that have been steamed are labelled with "St".

\subsection{Powder X-ray diffraction (XRD)}


Powder XRD patterns were obtained by use of a PANalytical X'pert diffractometer with a $\mathrm{Cu} \mathrm{K} \alpha$ X-ray source.

\subsection{Organic content}

The organic content of the samples was estimated using a Netzsch STA409PG TGA. Weight loss was calculated from the mass loss between 120 to $900{ }^{\circ} \mathrm{C}$, under a combined flow of $90 \mathrm{~mL} / \mathrm{min}$ of air and a $30 \mathrm{~mL} / \mathrm{min}$ of nitrogen. The data were collected between 25 and $900{ }^{\circ} \mathrm{C}$ heating at a rate of $10^{\circ} \mathrm{C} / \mathrm{min}$.

\subsection{Physisorption}

Nitrogen physisorption was performed on a Micrometrics Tristar 3020 instrument at $77 \mathrm{~K}$. Samples were degassed for 12 hours at $110^{\circ} \mathrm{C}$ prior to analysis. Surface area was calculated using the BET model. Pore volumes and pore-size distributions were calculated using the BdbFHH model [48].

\section{9. $\mathrm{CO}_{2}$ capacity measurements}

$\mathrm{CO}_{2}$ capacities were measured using a TA instruments Q500 TGA. Samples were pretreated under a $100 \mathrm{~mL} / \mathrm{min}$ flow of helium at $110{ }^{\circ} \mathrm{C}$ for 3 hours. The sorbent uptake was then measured from the gain in mass after subsequent exposure to $10 \% \mathrm{CO}_{2}$ in helium at $30{ }^{\circ} \mathrm{C}$, flowed at $90 \mathrm{~mL} / \mathrm{min}$ for $6 \mathrm{~h}$, with a $10 \mathrm{~mL} / \mathrm{min}$ balance helium flow.

\subsection{0. ${ }^{27}$ Al MAS NMR}

${ }^{27} \mathrm{Al}$ cross-polarization magic angle spinning (CP-MAS) solid-state nuclear magnetic resonance (NMR) measurements were carried out on a Bruker DSX-300 spectrometer. The samples had been exposed to atmospheric conditions (non-dehydrated) and were spun at a frequency of 10 $\mathrm{kHz}$, and 1024 scans were taken. 


\section{Results and discussions}

\subsection{Bare supports}

The bare mesoporous alumina supports (ordered: OAl and disordered: DAl) were each calcined at 4 different temperatures (400, 550, 700 and $\left.900{ }^{\circ} \mathrm{C}\right)$ to optimize their textural and physicochemical properties. The crystallinity of the systems, post calcination, was assessed using powder XRD (Fig. S1). The ordered system (OAl, Fig. S1a) shows only broad peaks at 37 and $47^{\circ}$, the (311) and (400) signals, respectively for poorly crystalline $\gamma-\mathrm{Al}_{2} \mathrm{O}_{3}[21,45,49]$. The peak intensity grows with increasing calcination temperature, with a peak at $39^{\circ}$ visible when calcined above $700{ }^{\circ} \mathrm{C}$. In contrast, calcining the disordered system (DAl, Fig. S1b) below 900 ${ }^{\circ} \mathrm{C}$ results in no significant features in the pattern. This confirms the lack of crystallinity in the system. However, on calcining at $900{ }^{\circ} \mathrm{C}$ (DAl900), $\gamma-\mathrm{Al}_{2} \mathrm{O}_{3}$ signals appear, showing that at higher temperatures the disordered system undergoes a phase change. We note that this observation differs from commercial samples, however this is attributed to the presence of mesopores influencing the surface chemistry.

Thermogravimetric analysis (TGA) combined with differential scanning calorimetry (DSC) gives us greater insight into the systems (Fig. S2). Both OAl400 and DAl400 show a noticeable decrease in mass around $500{ }^{\circ} \mathrm{C}$, which is also seen via DSC. These are attributed to residual organic species that were not removed on calcination at $400{ }^{\circ} \mathrm{C}$. For the ordered series (OAl, Fig. S2a) the combustible content decreases with increased calcination temperature, likely due to the dehydration of hydroxyl species. In contrast, DAl550 (Fig. S2b) has greater combustible mass than DAl400. For DAl550, the majority of the mass is lost in the $120-300{ }^{\circ} \mathrm{C}$ regime, which is likely due to the sorption of atmospheric species onto its strongly basic sites [45,50], or due to large quantities of surface hydroxyl species on removing the organic components. However, given the total mass lost is around $14 \mathrm{wt} \%$, it is unlikely that this is purely due to the removal of hydroxyl species.

$\mathrm{N}_{2}$ physisorption (Fig. S3) shows all systems have a type IV hysteresis, with mesoporosity and limited microporosity, in line with our previous findings [45]. The OAl series (Fig. S4) shows a linear decrease in surface area with calcination temperature, whereas the pore volume remains 
constant. Further the pore-size distributions (Fig. S5) show that the average pore size of the OAl materials increases, with a less uniform distrbution, as the calcination temperature increases (Fig. S5a). Reduction in surface area occurs as the pores become increasingly irregular, and can be attributed to sintering and the collapse of particles leading to larger pores [51]. In contrast, the pore volume and surface area of the DAl series reach a maximum for DAl-550 (Fig. S4), but decreases past this temperature. Here the pore size distribution appears to narrow, with the average pore diameter decreasing with increased calcination temperature (Fig. S5b). The initial increase in porosity is likely due to structural changes, as the combustible content of the DAl400 species is removed, clearing the pores and increasing the surface area and pore volume.

However, beyond $550{ }^{\circ} \mathrm{C}$, densification occurs as the phase change to $\gamma-\mathrm{Al}_{2} \mathrm{O}_{3}$ ensues. We note in both cases the pore distribution is not smooth, as expected in SBA-15, but is rougher, this is in line with our previous work on alumina samples [45].
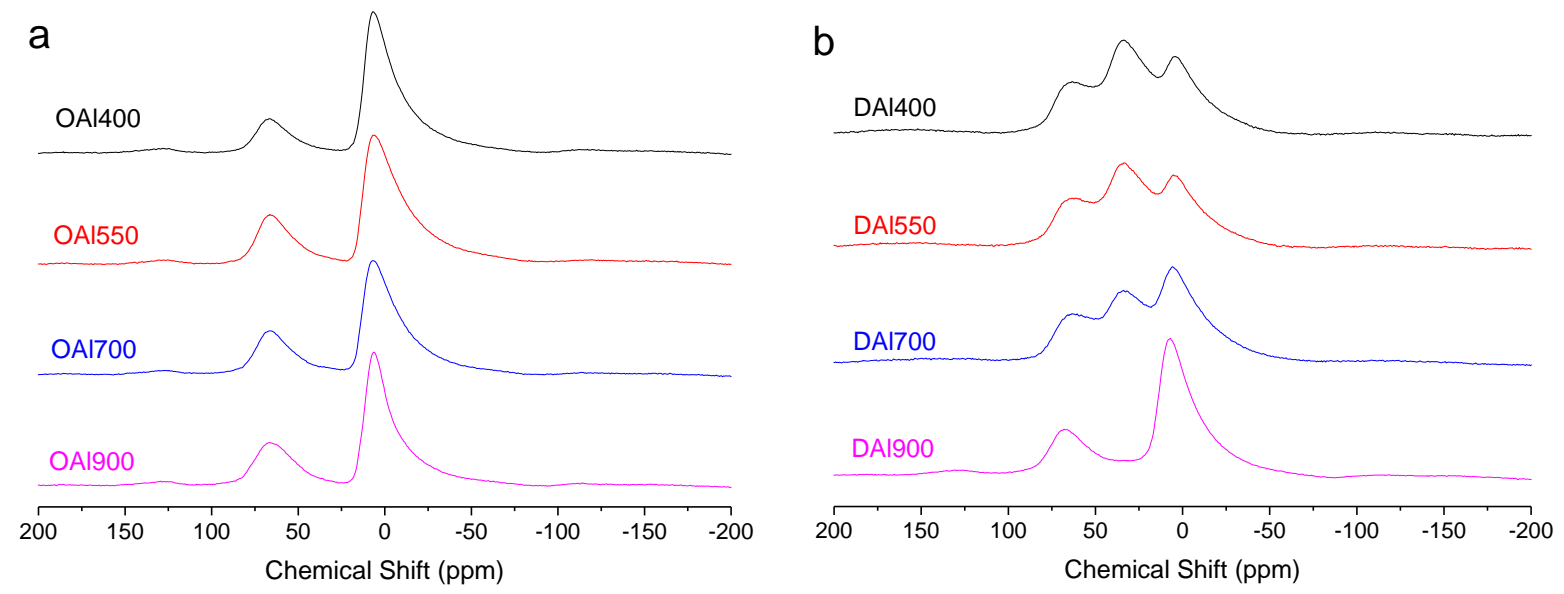

Fig. 1 Solid state MAS ${ }^{27} \mathrm{Al}$ NMR of bare, ordered (OAl, a) and bare, disordered (DAl, b) alumina species as a function of the original calcination temperature of the alumina. The spectra have been offset for clarity

${ }^{27} \mathrm{Al}$ MAS NMR was employed to probe the local structure of the alumina (Fig. 1). The ordered; OAl series shows two defined peaks at 66 and $6 \mathrm{ppm}$, in a 1:3 ratio, attributed to tetrahedral $\mathrm{AlO}_{4}$ and octahedral $\mathrm{AlO}_{6}$ respectively (Fig. 1a), in good agreement with $\gamma-\mathrm{Al}_{2} \mathrm{O}_{3}[21,45,49]$. Increasing the calcination temperature, increases the relative intensity of the tetrahedral signal, and a feature at $35 \mathrm{ppm}$ appears. This feature is attributed to $\mathrm{Al}_{\mathrm{v}}$, formed by dehydrating hydroxyl groups in $\gamma-\mathrm{Al}_{2} \mathrm{O}_{3}$, a known Lewis base site [52]. Thus, increasing the calcination 
temperature promotes lower coordinated aluminum, due to dehydration. DAl400 (Fig. 1b) shows three signals at 66, 35 and 4 ppm, again attributed to octahedral, pentacoordinate surface sites and tetrahedral aluminum respectively. As the calcination temperature increases, the pentacoordinate signal decreases as the octahedral species increases, showing a change from 5 to 6 coordinated aluminum. Once the calcination temperature reaches $900{ }^{\circ} \mathrm{C}$ (DAl900), the system resembles $\gamma-\mathrm{Al}_{2} \mathrm{O}_{3}$, in good agreement with XRD findings (Fig. S1).

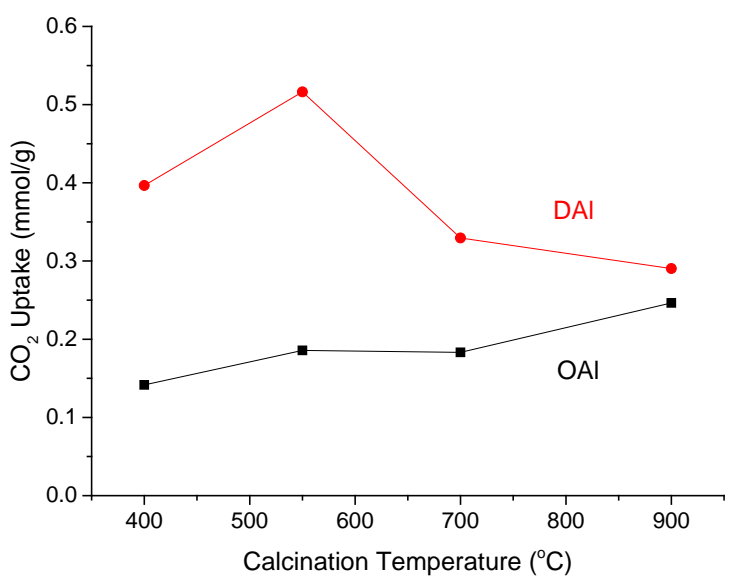

Fig. $2 \mathrm{CO}_{2}$ uptake of the bare, ordered (OAl, black) and bare, disordered (DAl, red) alumina, as a function of the original calcination temperature of the alumina. $\mathrm{CO}_{2}$ uptake measurements were done at $30{ }^{\circ} \mathrm{C}$, with dry $10 \% \mathrm{CO}_{2}$ in helium

The $\mathrm{CO}_{2}$ uptake of the bare supports show distinct trends for the two-different series (Fig. 2). The $\mathrm{CO}_{2}$ uptake of the $\mathrm{OAl}$ series increases as the calcination temperature increases, despite the reduced surface area (Fig. S4). This is likely due to the appearance of strong Lewis base, Alv sites, seen by ${ }^{27} \mathrm{Al}$ NMR (Fig. 1a), that would interact strongly with $\mathrm{CO}_{2}$, leading to a higher uptake for the bare support $[45,50]$. The $\mathrm{DAl}$ series adsorbs notably more $\mathrm{CO}_{2}$ than the $\mathrm{OAl}$ series, mirroring trends in our previous work [45], which were attributed to the presence of a large proportion of strongly basic $\mathrm{O}^{2-}$ species, capable of forming carbonates. The $\mathrm{CO}_{2}$ uptake follows a similar trend to the pore volume and surface area, peaking at DAl550, and then decreasing. This suggests that porosity is the key factor in $\mathrm{CO}_{2}$ sorption, as a greater surface area and pore volume improves the sorbents uptake behavior. 


\subsection{Steaming of bare supports}

The mesoporous alumina sorbents were then treated under simulated steam stripping conditions to investigate their stability, and suitability, for practical regeneration [39,40]. Powder XRD shows only subtle differences between the steamed (St-OAl) and fresh (OAl) series (Fig. S6), as features emerge at 39 and $49^{\circ}$, suggesting a small quantity of pseudo-boehmite has formed [5355]. The pore volume, surface area (Fig. 3a \& S7), pore-size distribution (Fig. 3b) and TGA data (Fig. S8) showed the steamed samples (St-OAl) were similar to the fresh samples (OAl). The ${ }^{27} \mathrm{Al}$ NMR spectra were also similar (Fig. 3b), though, the $\mathrm{Al}$ V feature in the ${ }^{27} \mathrm{Al}$ MAS NMR (36 $\mathrm{ppm}$ ) is no longer visible, likely it has been rehydrated to octahedral alumina. Overall this suggests the $\mathrm{OAl}$ series is relatively resilient to the simulated steam stripping conditions used.
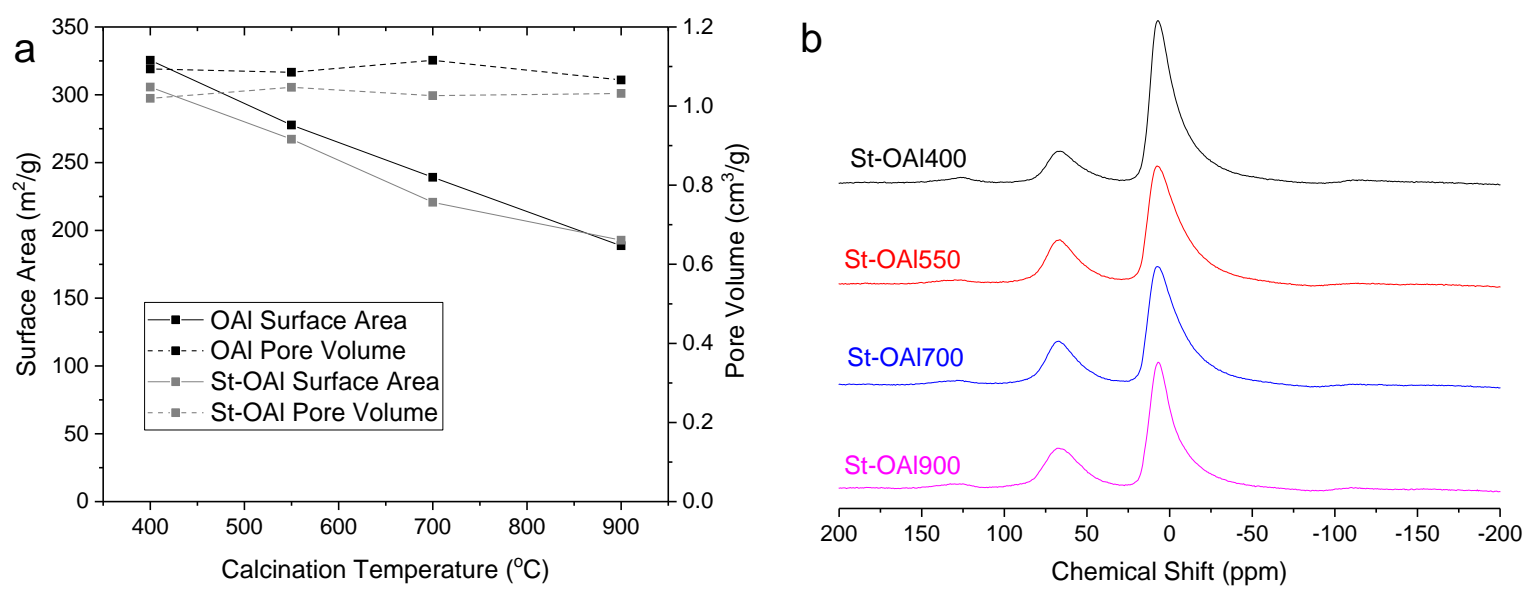

Fig. 3 a) The variation in surface area (solid lines) and pore volume (dashed lines) of bare ordered alumina (OAl, black) and after steaming (St-OAl, grey) as a function of the original calcination temperature of the alumina. b) Solid state MAS ${ }^{27} \mathrm{Al}$ NMR of steamed, bare, ordered (St-OAl) as a function of the original calcination temperature of the alumina. The spectra have been offset for clarity

In contrast, the DAl series undergoes substantial changes on steaming, as St-DAl400, St-DAl550 and St-DAl700 have a significant pseudo boehmite contribution (Fig. S9) [53-55]. However, StDAl900 is similar to the original DAl900 pattern, with only small contribution from pseudo boehmite at $49^{\circ}$. This suggests DAl900 was more resistant to steaming, likely due to the robust, crystalline $\gamma-\mathrm{Al}_{2} \mathrm{O}_{3}$ present. 
$\mathrm{N}_{2}$ physisorption shows that St-DAl400, St-DAl550 and St-DAl700 a now have a type III isotherm, with some residual porosity (Fig. S10a), as the surface areas and pore volumes reduced after steaming (Fig. 4a). Here, systems with pseudo boehmite present have greatly reduced pore volumes and surface areas, attributed to the dense nature of pseudo-bohemite [53]. However, the values St-DA1900 and DAl900 are comparable, suggesting little framework degradation has occurred. Again, the $\gamma-\mathrm{Al}_{2} \mathrm{O}_{3}$, formed on calcining at higher temperatures, likely makes the material more resistant to steaming (as previously seen in the St-OAl series), allowing the system to retain its physicochemical characteristics.

In the DAl series, the trends of surface area versus calcination temperature are reversed on steaming, as St-DAl550 is now a minimum (Fig. 4). This is also attributed to pseudo boehmite formation, which primarily occurs on the alumina surfaces via hydroxylation [53-55]. The more surface area available, the faster the rate of hydroxylation, leading to a greater proportion of dense phase material [53-55]. The pore size distribution (Fig. S10b) shows only St-DAl900 maintains mesoporosity (similar to DAl900). In contrast, the other three St-DAl samples present a featureless line, suggesting any porosity is highly disordered, again due to the structural changes on pseudo boehmite formation.
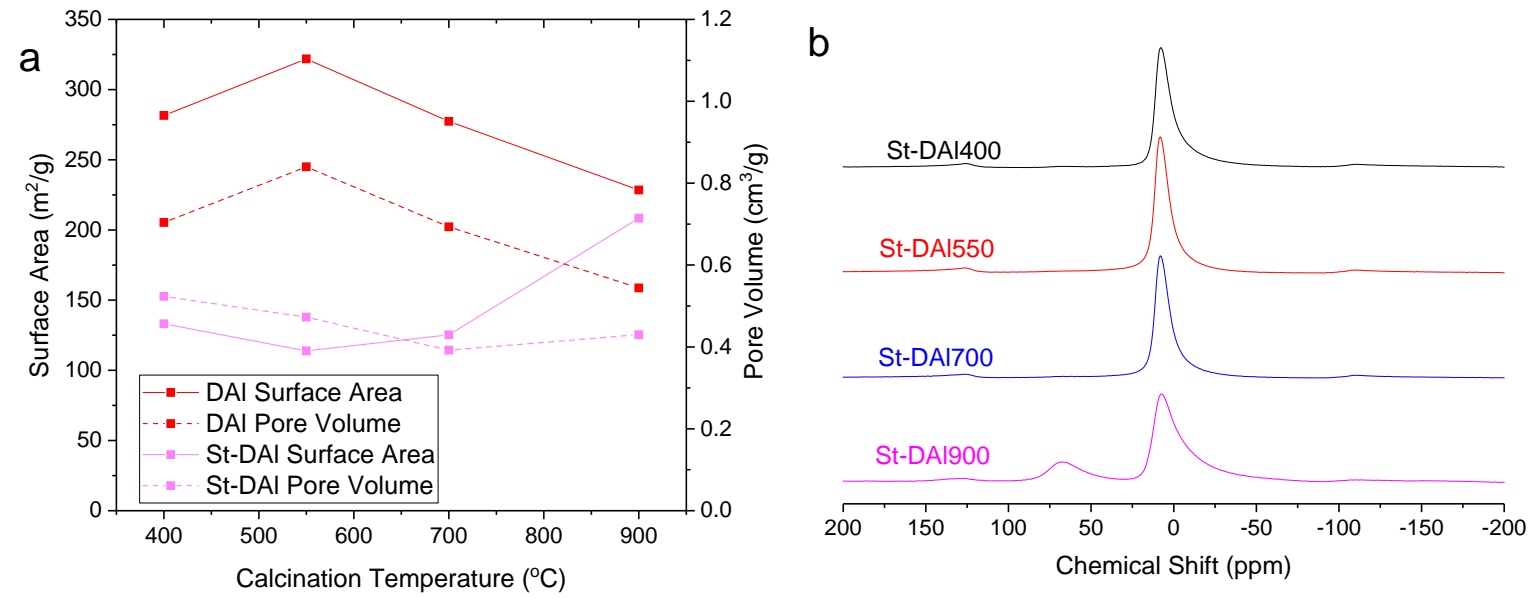

Fig. 4 a) The variation in surface area (solid lines) and pore volume (dashed lines) of bare disordered alumina (DAl, red) and after steaming (St-DAl, pink) as a function of the original calcination temperature of the alumina. b) Solid state MAS ${ }^{27} \mathrm{Al}$ NMR of steamed, bare, disordered (St-DAl) as a function of the original calcination temperature of the alumina. The spectra have been offset for clarity 
TGA (Fig. S11) and NMR (Fig. 4b) also show pseudo boehmite formation. St-DAl400, StDAl550 and St-DAl700 show a greater weight loss than the pre-steamed samples, and StDAl900, due to the dehydration of the pseudo boehmite (AlOOH) to alumina $\left(\mathrm{Al}_{2} \mathrm{O}_{3}\right)$ at elevated temperatures. However, there is also likely to be some adsorbed water and defect surface species present in steamed samples, explaining the larger weight loss. The DSC (Fig. S11) also highlights the difference in the two structures, with a signal at $400{ }^{\circ} \mathrm{C}$, attributed to the dehydration of pseudo boehmite. St-DAl900 shows only a subtle signal at $450{ }^{\circ} \mathrm{C}$, due to the small quantity of pseudo boehmite formed (as seen by powder XRD, Fig. S9). The NMR data (Fig. 4b) are in good agreement with these findings, as St-DAl900 resembles the unsteamed DAl900, whereas the other three samples presenting a single signal attributed to octahedral $\mathrm{AlO}_{6}$ at $7 \mathrm{ppm}$, typical of pseudo boehmite [53-55]. The lack of tetrahedral Al signal (60 - $70 \mathrm{ppm})$ suggests that pseudo boehmite is now the dominant phase in the sample [53-55].

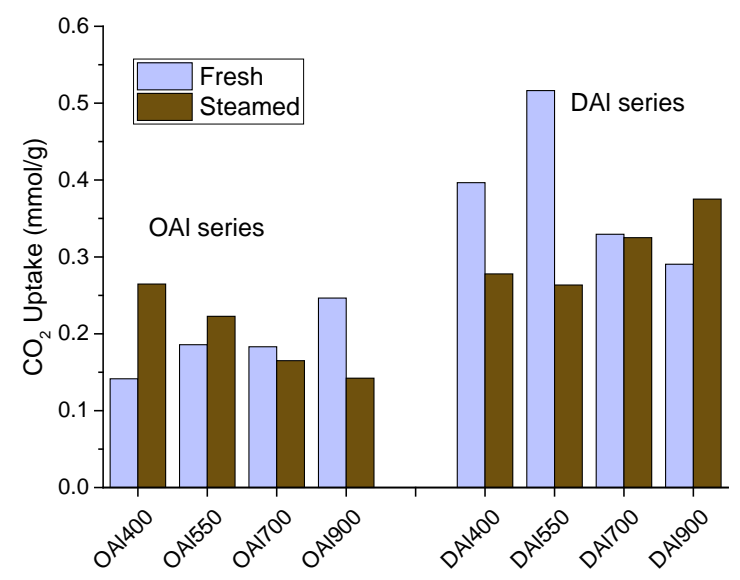

Fig. $5 \mathrm{CO}_{2}$ uptake of the bare, ordered (OAl, left) and bare, disordered (DAl, right) series for fresh samples (pale blue), and after steaming (brown), as a function of the original calcination temperature of the alumina. $\mathrm{CO}_{2}$ uptake measurements were made at $30{ }^{\circ} \mathrm{C}$, with dry $10 \% \mathrm{CO}_{2}$ in helium

The $\mathrm{CO}_{2}$ uptake of both sets of steamed supports differed from the fresh series (Fig. 5). Fresh OAl showed a higher $\mathrm{CO}_{2}$ uptake when calcined at higher temperature, attributed to the dehydration of octahedral species to form strong Lewis base $\mathrm{Al}_{\mathrm{V}}$ defect sites, capable of interaction with $\mathrm{CO}_{2}$ [45]. The reverse trend is seen on steaming, with the St-OAl series showing higher $\mathrm{CO}_{2}$ uptake for samples with lower original calcination temperature, following the same 
trend as the surface area. This is likely because steaming over 24 hours saturated the surface with hydroxyl species that can bind to $\mathrm{CO}_{2}$ [56]. Thus, a higher surface area means more hydroxyl groups, correlating with a greater $\mathrm{CO}_{2}$ uptake. The $\mathrm{CO}_{2}$ uptake of the disordered (DAl) series also follows the same trend as surface area, again likely due to hydroxyl formation on the surface after steaming.

\subsection{PEI-Impregnated Supports}

The steam stability of PEI impregnated aluminas was investigated, with the supports (calcined at different temperatures) impregnated with PEI, and then steamed. The powder XRD patterns of the PEI impregnated OAl series (PEI-OAl, Fig. 6a) agree with the undoped bare OAl species (Fig. S1a), showing just $\gamma-\mathrm{Al}_{2} \mathrm{O}_{3}$ features. On steaming the PEI-OAl series, features attributed to pseudo boehmite emerge, for all samples except St-PEI-OAl900, which again appears to be resilient (Fig. 6a). Contrasting the St-OAl and St-PEI-OAl series shows PEI-impregnated species contain more pseudo boehmite. Thus, the amines in PEI may accelerate pseudo boehmite formation on steaming. The steaming of PEI-DAl (Fig. 6b) results in the significant formation of pseudo boehmite in St-PEI-DAl400, St-PEI-DAl550 and St-PEIDAl700. Previously St-DAl900 retained its $\gamma-\mathrm{Al}_{2} \mathrm{O}_{3}$ features (Fig. S9); however, again it appears the inclusion of PEI has accelerated the formation of pseudo boehmite, as these features are now prominent in St-PEIDAl900 (Fig. 6b).
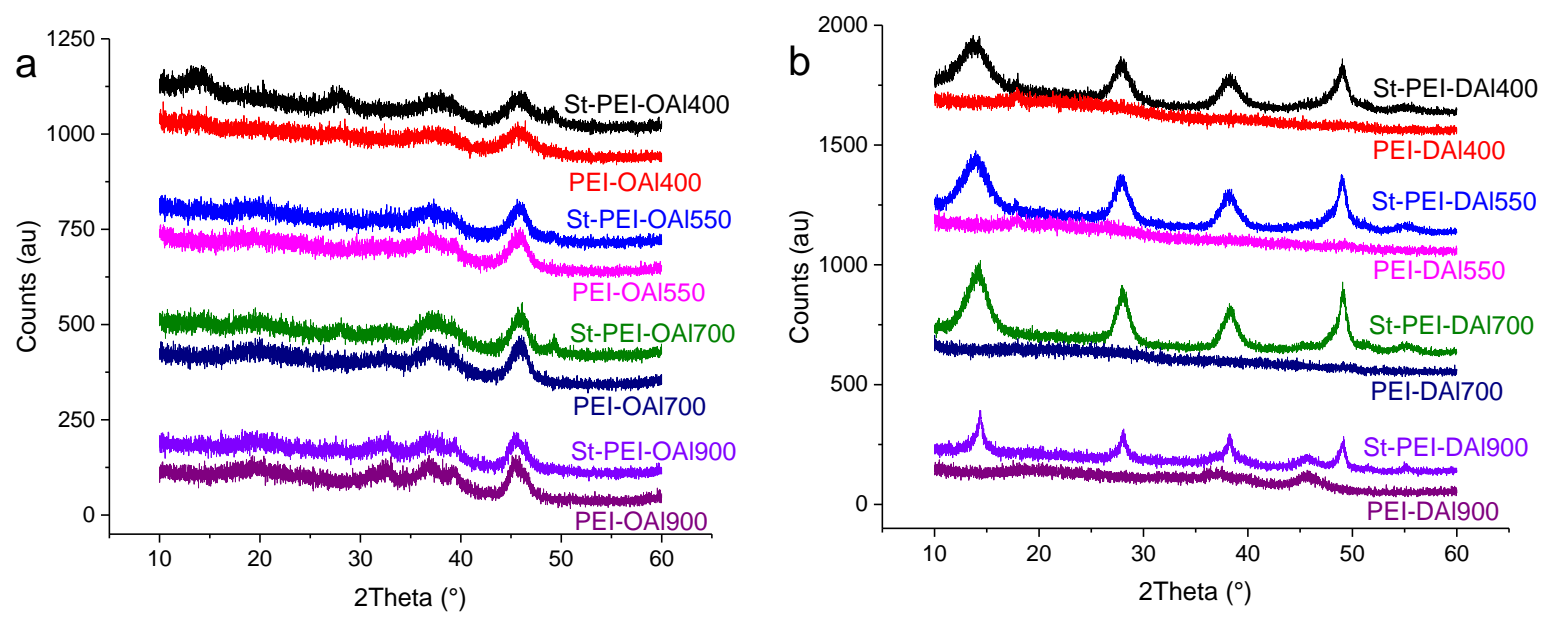
Fig. 6 Wide angle powder XRD patterns of a) PEI-impregnated, ordered alumina, both before (PEI-OAl) and after steaming (St-PEI-OAl) and b) PEI-impregnated, disordered alumina, both before (PEI-DAl) and after steaming (St-PEI-DAl) as a function of the original calcination temperature of the alumina. The patterns in are offset by 75 counts in a, 100 counts in b, between fresh and steamed samples, with different calcination temperatures offset by 300 counts in a, 500 counts in b, for clarity

TGA data quantified the PEI loading in the impregnated samples (Fig. S12 \& S13). For both the PEI-OAl and PEI-DAl series, the amine loading was found to be $9-13 \mathrm{mmol}$ of amine/g of alumina (Fig. S12a \& S13a). Previous literature shows there is minimal leaching under simulated steam conditions, thus, the amine loading is not expected to vary significantly, post-steaming, in these systems [40,41]. However changes in our TGA data on steaming PEI-containing species (Fig. S12b \& S13b) could be due to many factors, including strongly-bound water, hydroxyl formation, amine degradation, etc. [1], meaning accurate comparisons cannot be made based purely on the support. Again steamed St-PEI-DAl (Fig. S13b) series shows a greater weight loss than fresh PEI-DAl (Fig. S13a), partially due to pseudo boehmite formation. The DSC data in all cases was dominated by a signal at $200{ }^{\circ} \mathrm{C}$, not seen in the bare supports, attributed to the presence of PEI. However, no notable variations could be solely attributed to the support for the PEI-containing samples, regardless of steaming, or alumina type.
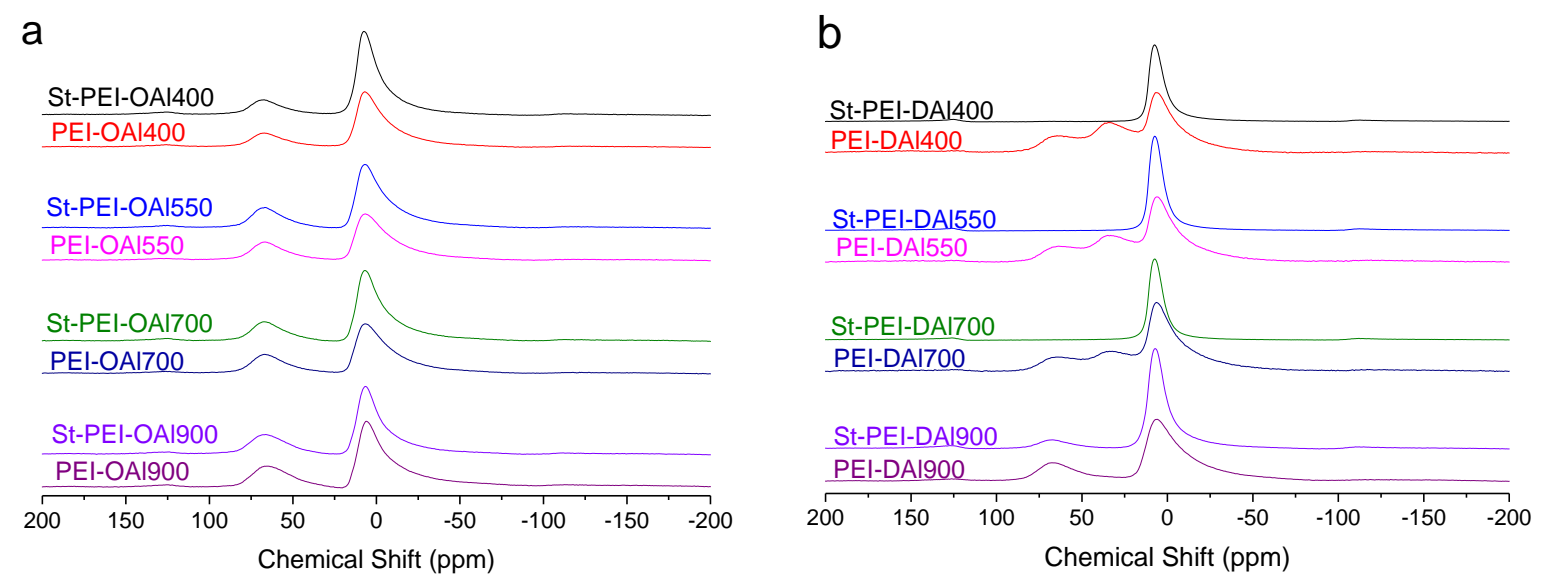

Fig. 7 Solid state MAS ${ }^{27} \mathrm{Al}$ NMR of a) PEI-impregnated, ordered alumina, before (PEI-OAl) and after steaming (St-PEI-OAl), and b) PEI-impregnated, disordered alumina, before (PEI-DAl) 
and after steaming (St-PEI-DAl) as a function of the original calcination temperature of the alumina. The spectra have been offset for clarity and ease of comparison

${ }^{27} \mathrm{Al}$ MAS NMR shows little differences between the St-PEI-OAl and PEI-OAl series, (Fig. 7a) as both show a tetrahedral $\mathrm{AlO}_{4}$ signal at $68 \mathrm{ppm}$, and an intense octahedral $\mathrm{AlO}_{6}$ signal at 7 ppm, in a 1:3 ratio, akin to the bare OAl series (Fig. 3b). The only subtle difference is St-PEIOAl900 has a greater proportion of octahedral sites than PEI-OAl900, likely due to the pseudo boehmite formation. The PEI-DAl series (Fig. 7b) is similar to the bare DAl series (Fig. 4b), except the $\mathrm{Al}_{V}$ site at $33 \mathrm{ppm}$ is less intense on PEI impregnation, likely due to the interaction between PEI and the basic sites, converting the $\mathrm{Al}_{\mathrm{v}}$ sites to octahedral aluminum, overlapping with the $\mathrm{AlO}_{6}$ signal. Again on steaming the PEI-DAl series the first three samples suggest pseudo boehmite is the dominant phase (Fig. 7b), with just one peak present at 7 ppm, representing octahedral alumina. Comparing St-PEI-OAl900 (Fig. 7a) with St-OAl900 (Fig. 3b) shows the former has a larger proportion of octahedral Al, whereas the latter is closer to the expected 1:3 ratio, typical of $\gamma-\mathrm{Al}_{2} \mathrm{O}_{3}$. This again is due to the amine groups of the PEI accelerating the formation of pseudo boehmite.
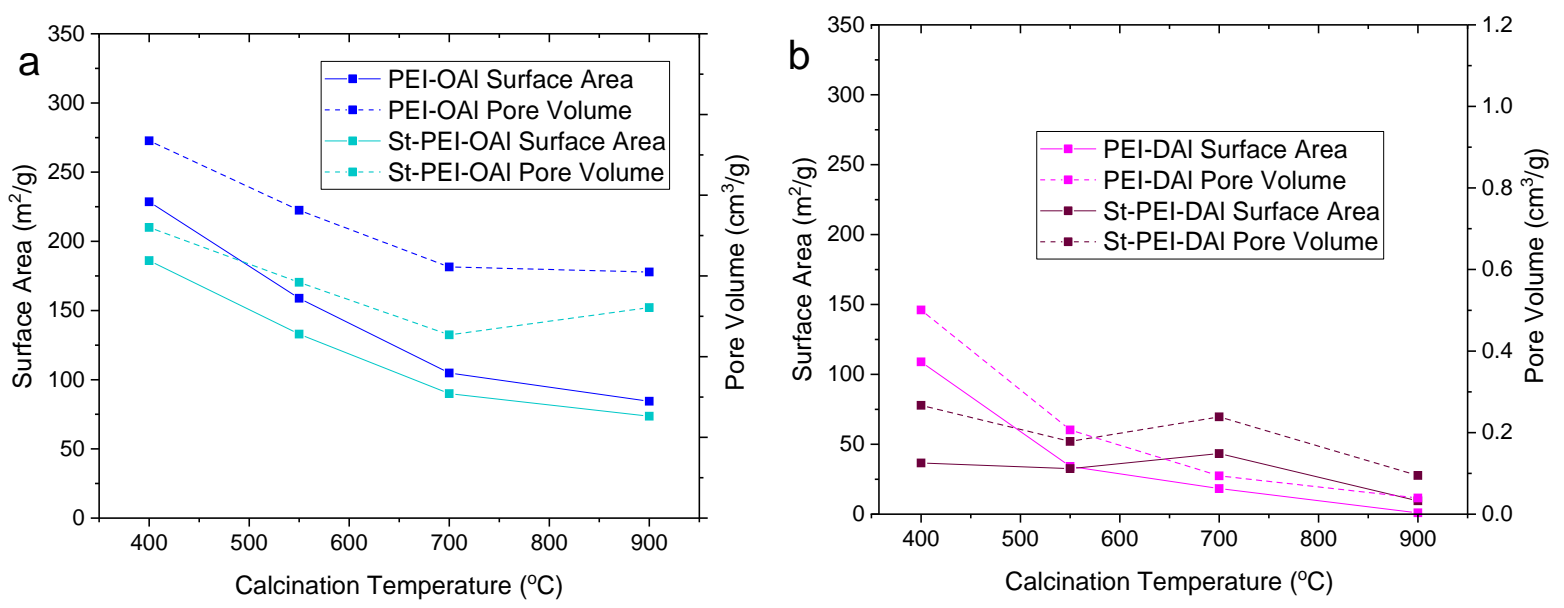

Fig. 8 Showing the variation in surface area (solid lines) and pore volume (dashed lines) of a) PEI-impregnated, ordered alumina, before (PEI-OAl, blue) and after steaming (St-PEI-OAl, cyan) and b) PEI-impregnated, disordered alumina, before (PEI-DAl, magenta) and after steaming (St-PEI-DAl, purple) as a function of the original calcination temperature of the alumina 
Physisorption data of the PEI-OAl series shows a decrease in pore volume and surface area on introducing PEI (Fig. 8a), causing a narrower pore distribution (Fig. S14b), and lower average pore dimeter, as PEI coats the walls of the mesopores, as seen in SBA-15 [58]. On steaming, the PEI-OAl series maintains its porosity (St-PEI-OAl), showing only slight variation in isotherms (Fig. S14a) and pore-size distributions (Fig. S14b). This is in good agreement with powder XRD (Fig. 6a) and ${ }^{27} \mathrm{Al}$ NMR findings (Fig. 7a), showing the resilience of the ordered alumina. The surface areas and pore volumes of PEI-OAl decrease on steaming (Fig. 8a), due to pseudo boehmite formation, as seen in the XRD.

Impregnation of PEI into the DAl series (PEI-DAl) also reduced pore volume and surface area (Fig. 8b). Further, the inclusion of PEI results causes differences in the support behavior on steaming. The $\mathrm{N}_{2}$ isotherms of both the PEI-DAl and St-PEI-DAl show a type IV isotherm (Fig. S15), whereas St-DAl had a type III isotherm (Fig. S10a). This suggests PEI helps maintain the porosity. This can also be seen in the pore-size distributions, where the PEI-DAl maintains a similar pore-size distribution as the DAl system (Fig. 9). When PEI was absent, there was no signs of mesoporosity after steaming (St-DAl), whereas all St-PEI-DAl samples do show mesoporosity is present after steaming. The PEI may act like a template, preserving the mesopores around it, therefore polymeric/oligomeic species could create defined mesoporosity, serving as steam stable $\mathrm{CO}_{2}$ sorbents. However, the surface areas and pore volumes of PEI-DAl still decrease on steaming, again attributed to the formation of dense-phase pseudo boehmite as seen in the XRD pattern (Fig. 8b).

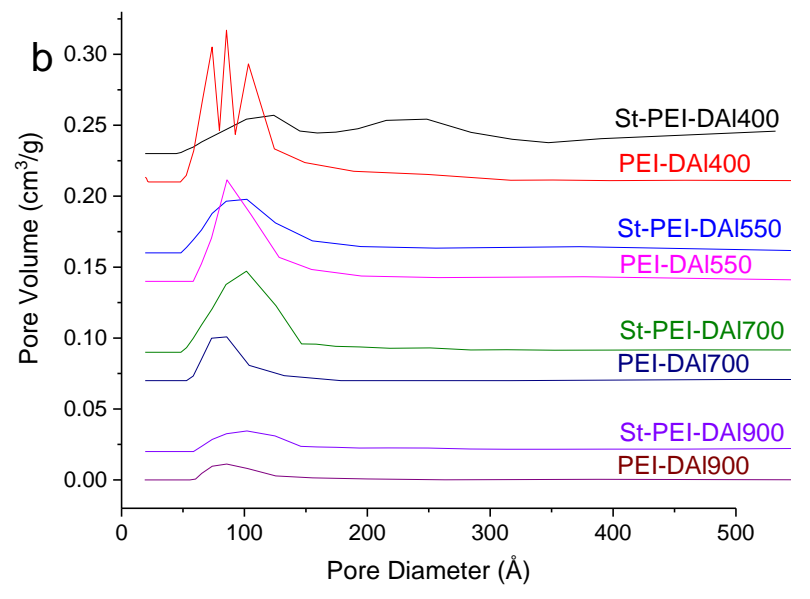


Fig. 9 Pore size distributions analyzed by the BdB-FHH method of fresh PEI-impregnated disordered alumina (PEI-DAl), and after steaming (St-PEI-DAl). The distributions are offset by $0.02 \mathrm{~cm}^{3} / \mathrm{g}$ between analogous fresh and steamed samples, and by $0.07 \mathrm{~cm}^{3} / \mathrm{g}$ between the original alumina calcination temperatures, for clarity

The PEI impregnated systems were tested for $\mathrm{CO}_{2}$ uptake under simulated flue gas conditions, comparing fresh species with steamed (Fig. 10). The $\mathrm{CO}_{2}$ uptake is improved considerably on PEI impregnation, due to available amine sites. The PEI-DAl and PEI-OAl able to maintain their $\mathrm{CO}_{2}$ uptakes on steaming; in most cases, the capacity varies by less than $5 \%$. Two notable exceptions to this are PEI-OAl700 and PEI-DAl700. The onset of pseudo boehmite is most pronounced for St-PEI-OAl700 in the St-PEI-OAl series, with a peak clearly visible at $49^{\circ}$. The associated changes in surface chemistry is the most likely the cause of the reduced $\mathrm{CO}_{2}$ uptake, with dense phase pseudo boehmite limiting $\mathrm{CO}_{2}$ diffusion, blocking access to the amine sites in PEI. The other distinct deviation, St-PEI-DAl700, is likely the result of a change in porosity. Both surface area and pore volume in St-PEI-DAl700 are notably higher than the rest of the series, and also higher than PEI-DAl700. The improvements to the surface area on steaming may alter the morphology of the PEI, or improve $\mathrm{CO}_{2}$ diffusion, allowing more amine sites to interact with the $\mathrm{CO}_{2}$. To further emphasize the importance of surface area and pore volume for PEIimpregnated species, comparing the amine efficiencies of the fresh samples (PEI-OAl and PEIDAl) shows the amines are more effective $\mathrm{CO}_{2}$ sorbents in PEI-OAl (Fig. S16). This is likely due to the higher surface areas and pore volumes of the PEI-OAl series compared to PEI-DAl. We note in all cases the amine efficiency is less than $25 \%$, which is below the theoretical maximum of $39 \%$ for these branched PEI samples ( $4: 3: 2$ of $1^{\circ}: 2^{\circ}: 3^{\circ}$ amines), suggesting the PEI is operating below maximum efficiency. 


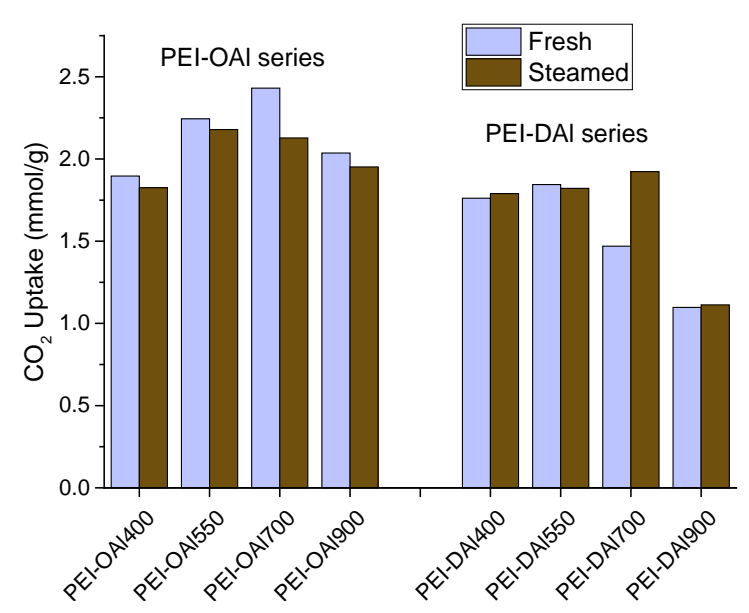

Fig. $10 \mathrm{CO}_{2}$ uptake of the PEI-impregnated, ordered (PEI-OAl, left) and PEI-impregnated, disordered (PEI-DAl, right) series for fresh samples (pale blue), and after steaming (brown), as a function of the original calcination temperature of the alumina. $\mathrm{CO}_{2}$ uptake measurements were made at $30{ }^{\circ} \mathrm{C}$, with dry $10 \% \mathrm{CO}_{2}$ in helium

\section{Conclusions}

To effectively design $\mathrm{CO}_{2}$ sorbents, a wide range of criteria must be satisfied, including the practical regeneration of the sorbent. While the benefits of different regeneration techniques are being debated for amine-containing sorbents, steam stability is crucial for steam-stripping regeneration, and is a vital for $\mathrm{CO}_{2}$ adsorption for flue gas sorption from industrial point sources. As such, mesoporous alumina is a viable support for amine-based sorbents, given the stability of the system. By comparing a range of alumina supports, we have shown that local crystallinity, such as $\gamma-\mathrm{Al}_{2} \mathrm{O}_{3}$, improves steam stability, by preventing the formation of pseudo boehmite, which limits the $\mathrm{CO}_{2}$ uptake of the bare sorbent. In light of this, we demonstrate that steam stripping can have a significant influence on the nature of framework sites for $\mathrm{CO}_{2}$ sorption. Namely, the rehydration of coordinatively unsaturated alumina sites in the ordered alumina, which was found to hinder $\mathrm{CO}_{2}$ uptake. However, once hydrated through steaming, the uptake of the alumina sample is directly linked to the porosity of the sample, where species with high surface areas and pore volumes show the best $\mathrm{CO}_{2}$ uptake behavior. This is likely the result of the surface becoming saturated with surface hydroxyl species. Further we show that while the amine sites of PEI drastically improve the $\mathrm{CO}_{2}$ uptake, they can facilitate the transformation of 
the alumina structure to pseudo boehmite. However, in spite of this, the aminopolymer is also able to act as a template, forcing the alumina to retain its mesoporosity on steaming, resulting in pseudo boehmite with defined mesopores. Overall, we have probed the complex behavior of alumina supports, and their stability towards steam. We believe that this work has offers practical insights towards designing improved $\mathrm{CO}_{2}$ sorbents for flue gas capture.

\section{$\underline{\text { 5. Funding Sources }}$}

This work was supported by the Center for Understanding and Control of Acid Gas-Induced Evolution of Materials for Energy (UNCAGE-ME), an Energy Frontier Research Center, funded by U.S. Department of Energy (US DoE), Office of Science, Basic Energy Sciences (BES) under Award DE-SC0012577.

\section{References}

[1] Choi S, Gray ML and Jones CW (2011) Amine-tethered solid adsorbents coupling high adsorption capacity and regenerability for $\mathrm{CO}_{2}$ capture from ambient air, ChemSusChem 4:628635.

[2] Bonan CB (2008) Forests and Climate Change: Forcings, Feedbacks and the Climate Benefits of Forests, Science 320:1444-1449.

[3] Sanz-Perez ES, Murdock CR, Didas SA and Jones CW (2016) Direct Capture of $\mathrm{CO}_{2}$ from Ambient Air, Chem Rev 116:11840-11876.

[4] IEA. (2012) $\mathrm{CO}_{2}$ emissions from fuel combustion Highlights; OECD/IEA: Paris.

[5] Fisher JC and Gray M (2015) Cyclic stability testing of aminated-silica solid sorbent for postcombustion $\mathrm{CO}_{2}$ capture, ChemSusChem 8: 452-455.

[6] Wang Q, Luo J, Zhong Z and Borgna A (2011) $\mathrm{CO}_{2}$ capture by solid adsorbents and their applications: current status and new trends, Energy Environ Sci 4: 42-55.

[7] Bae TH, Hudson MR, Mason JA, Queen WL, Dutton JJ, Sumida K, Micklash KJ, Kaye SS, Brown CM and Long JR (2013) Evaluation of cation-exchanged zeolite adsorbents for postcombustion carbon dioxide capture, Energy Environ Sci 6:128-138. 
[8] Fracaroli AM, Furukawa H, Suzuki M, Dodd M, Okajima S, Gandara F, Reimer JA and Yaghi OM (2014) Metal-Organic Frameworks with Precisely Designed Interior for Carbon Dioxide Capture in the Presence of Water, J Am Chem Soc 136:8863-8866.

[9] Chai SH, Liu ZM, Huang K, Tan S and Dai S (2016) Amine Functionalization of Microsized and Nanosized Mesoporous Carbons for Carbon Dioxide Capture, Ind Eng Chem Res 55:73557361.

[10] Wang S, Yan S, Ma X and Gong J (2011) Recent advances in capture of carbon dioxide using alkali-metal-based oxides, Energy Environ Sci 4: 3805-3819.

[11] Sayari A and Belmabkhout Y (2010) Stabilization of Amine-Containing $\mathrm{CO}_{2}$ Adsorbents: Dramatic Effect of Water Vapor, J Am Chem Soc 132:6312-6314. [12] Dutcher B, Fan M and Russell AG (2015) Amine-Based $\mathrm{CO}_{2}$ Capture Technology Development from the Beginning of 2013-A Review, ACS Appl Mater Interfaces 7:2137-2148. [13] Goeppert A, Czaun M, May RB, Prakash GKS, Olah GA and Narayanan SR (2011) Carbon Dioxide Capture from the Air Using a Polyamine Based Regenerable Solid Adsorbent, J Am Chem Soc 133:20164-20167.

[14] Sanz R, Calleja G, Arencibia A and Sanz-Perez ES (2015) $\mathrm{CO}_{2}$ capture with pore-expanded MCM-41 silica modified with amino groups by double functionalization, Microporous Mesoporous Mater 209:165-171.

[15] Wang XX, Ma XL, Schwartz V, Clark JC, Overbury SH, Zhao SQ, Xu XC and Song C (2012) A solid molecular basket sorbent for $\mathrm{CO}_{2}$ capture from gas streams with low $\mathrm{CO}_{2}$ concentration under ambient conditions, Phys Chem Chem Phys 14:1485-1492.

[16] Son WJ, Choi JS and Ahn WS (2008) Adsorptive removal of carbon dioxide using polyethyleneimine-loaded mesoporous silica materials, Microporous Mesoporous Mater 113:3140.

[17] Wang D, Ma X, Sentorun-Shalaby C and Song C (2012) Development of Carbon-Based “Molecular Basket” Sorbent for $\mathrm{CO}_{2}$ Capture, Ind Eng Chem Res 51:3048-3057. [18] Heydari-Gorji A, Belmabkhout Y and Sayari A (2011) Polyethylenimine-Impregnated Mesoporous Silica: Effect of Amine Loading and Surface Alkyl Chains on $\mathrm{CO}_{2}$ Adsorption, Langmuir 27:12411-12416. 
[19] Choi W, Min K, Kim C, Ko YS, Jeon J, Seo H, Park YK and Choi M (2016) Epoxidefunctionalization of polyethyleneimine for synthesis of stable carbon dioxide adsorbent in temperature swing adsorption, Nature Commun 7:12640.

[20] Niu MY, Yang HM, Zhang XC, Wang YT and Tang AD (2016) Amine-Impregnated Mesoporous Silica Nanotube as an Emerging Nanocomposite for $\mathrm{CO}_{2}$ Capture, ACS Appl Mater Interface 8:17312-17320.

[21] Bali S, Leisen J, Foo GS, Sievers C and Jones CW (2014) Aminosilanes Grafted to Basic Alumina as $\mathrm{CO}_{2}$ Adsorbents-Role of Grafting Conditions on $\mathrm{CO}_{2}$ Adsorption Properties, ChemSusChem 7:3145-3156.

[22] Zheng F, Tran DN, Busche BJ, Fryxell GE, Addleman RS, Zemanian TS and Aardahl CL (2005) Ethylenediamine-Modified SBA-15 as Regenerable $\mathrm{CO}_{2}$ Sorbent, Ind Eng Chem Res 44:3099-3105.

[23] Zelenak V, Skrinska M, Zukal A and Cejka J (2018) Carbon dioxide adsorption over amine modified silica: Effect of amine basicity and entropy factor on isosteric heats of adsorption, Chem Eng J 348:327-337.

[24] Drese JH, Choi S, Lively RP, Koros WJ, Fauth DJ, Gray ML and Jones CW (2009) Synthesis-Structure-Property Relationships for Hyperbranched Aminosilica $\mathrm{CO}_{2}$ Adsorbents, Adv Funct Mater 19:3821-3832.

[25] Wilfong WC, Kail BW, Jones CW, Pacheco C and Gray ML (2016) Spectroscopic Investigation of the Mechanisms Responsible for the Superior Stability of Hybrid Class 1/Class 2 $\mathrm{CO}_{2}$ Sorbents: A New Class 4 Category, ACS Appl Mater Interfaces 8:12780-12791. [26] Fujiki J, Chowdbury FA, Yamada H and Yogo K (2017) Highly efficient post-combustion $\mathrm{CO}_{2}$ capture by low-temperature steam-aided vacuum swing adsorption using a novel polyamine-based solid sorbent, Chem Eng J 307:273-282.

[27] Hammache S, Hoffman JS, Gray ML, Fauth DJ, Howard BH and Pennline HW (2013) Comprehensive Study of the Impact of Steam on Polyethyleneimine on Silica for $\mathrm{CO}_{2}$ Capture, Energy Fuels 27:6899-6905.

[28] Li KM, Jiang JG, Tian SC, Yan F and Chen XJ (2015) Polyethyleneimine-nano silica composites: a low-cost and promising adsorbent for $\mathrm{CO}_{2}$ capture, J Mater Chem A 3:2166-2175. [29] Zhao W, Zhang Z, Li Z and Cai N (2013) Investigation of Thermal Stability and Continuous $\mathrm{CO}_{2}$ Capture from Flue Gases with Supported Amine Sorbent, Ind Eng Chem Res 52:2084-2093. 
[30] Sakwa-Novak MA, Yoo CJ, Tan S, Rashidi F and Jones CW (2016) Poly(ethylenimine)Functionalized Monolithic Alumina Honeycomb Adsorbents for $\mathrm{CO}_{2}$ Capture from Air, ChemSusChem 9:1859-1868.

[31] Ebner AD, Gray ML, Chisholm NG, Black QT, Mumford DD, Nicholson MA and Ritter JA (2011) Suitability of a Solid Amine Sorbent for $\mathrm{CO}_{2}$ Capture by Pressure Swing Adsorption, Ind Eng Chem Res 50:5634-5641.

[32] Mane S, Gao ZY, Li YX, Liu XQ, and Sun LB (2018) Rational Fabrication of Polyethylenimine-Linked Microbeads for Selective $\mathrm{CO}_{2}$ Capture, Ind Eng Chem Res 57:250258.

[33] Zhou Z, Balijepalli SK, Nguyen-Sorenson AHT, Anderson CM, Park JL and Stowers KJ (2018) Steam-Stable Covalently Bonded Polyethylenimine Modified Multiwall Carbon Nanotubes for Carbon Dioxide Capture, Energy Fuels 32:11701-11709.

[34] Sakwa-Novak MA and Jones CW (2014) Steam Induced Structural Changes of a Poly(ethylenimine) Impregnated $\gamma$-Alumina Sorbent for $\mathrm{CO}_{2}$ Extraction from Ambient Air, ACS Appl Mater Interfaces 6:9245-9255.

[35] Gunathilake C, Gangoda M and Jaroniec M (2016) Mesoporous Alumina with Amidoxime Groups for $\mathrm{CO}_{2}$ Sorption at Ambient and Elevated Temperatures, Ind Eng Chem Res 55:55985607.

[36] Li W, Bollini P, Didas SA, Choi S, Drese JH and Jones CW (2010) Structural Changes of Silica Mesocellular Foam Supported Amine-Functionalized $\mathrm{CO}_{2}$ Adsorbents Upon Exposure to Steam, ACS Appl Mater Interfaces 2:3363-3372.

[37] Isenberg $\mathrm{M}$ and Chaung SSC (2013) The Nature of Adsorbed $\mathrm{CO}_{2}$ and Amine Sites on the Immobilized Amine Sorbents Regenerated by Industrial Boiler Steam, Ind Eng Chem Res 52:12530-12539.

[38] Drage TC, Arenillas A, Smith KM and Snape CE (2008) Thermal stability of polyethylenimine based carbon dioxide adsorbents and its influence on selection of regeneration strategies, Microporous Mesoporous Mater 116:504-512.

[39] Li W, Choi S, Drese JH, Hornbostel M, Krishnan G, Eisenberger PM and Jones CW (2010) Steam-stripping for regeneration of supported amine-based $\mathrm{CO}_{2}$ adsorbents, ChemSusChem 3:899-903. 
[40] Chaikittisilp W, Kim HJ and Jones CW (2011) Mesoporous Alumina-Supported Amines as Potential Steam-Stable Adsorbents for Capturing $\mathrm{CO}_{2}$ from Simulated Flue Gas and Ambient Air, Energy Fuels 25:5528-5537.

[41] Sandhu NK, Pudasainee D, Sarkar P and Gupta R (2016) Steam Regeneration of Polyethylenimine-Impregnated Silica Sorbent for Postcombustion $\mathrm{CO}_{2}$ Capture: A Multicyclic Study, Ind Eng Chem Res 55:2210-2220.

[42] Fayaz M and Sayari A (2017) Long-Term Effect of Steam Exposure on $\mathrm{CO}_{2}$ Capture Performance of Amine-Grafted Silica, ACS Appl Mater Interfaces 9:43747-43754.

[43] Wilfong WC, Kail BW and Gray ML (2015) Rapid Screening of Immobilized Amine $\mathrm{CO}_{2}$ Sorbents for Steam Stability by Their Direct Contact with Liquid $\mathrm{H}_{2} \mathrm{O}$, ChemSusChem 8:20412045.

[44] Min K, Choi W, Choi M (2017) Macroporous Silica with Thick Framework for SteamStable and High-Performance Poly(ethyleneimine)/Silica $\mathrm{CO}_{2}$ Adsorbent, ChemSusChem 10:2518-2526.

[45] Potter ME, Cho KM, Lee JJ and Jones CW (2017) Role of Alumina Basicity in $\mathrm{CO}_{2}$ Uptake in 3-Aminopropylsilyl-Grafted Alumina Adsorbents, ChemSusChem 10: 2192-2201.

[46] Sievers C, Noda Y, Qi L, Albuquerque EM, Rioux RM and Scott SL (2016) Phenomena Affecting Catalytic Reactions at Solid-Liquid Interfaces, ACS Catal 6:8286-8307.

[47] Ciftci A, Peng B, Jentys A, Lercher JA and Hensen EJM (2012) Support effects in the aqueous phase reforming of glycerol over supported platinum catalysts, Appl Catal A Gen 431432:113-119.

[48] Lukens WW, Schmidt-Winkel P, Zhao D, Feng J and Stucky GD (1999) Evaluating Pore Sizes in Mesoporous Materials: A Simplified Standard Adsorption Method and a Simplified Broekhoff-de Boer Method, Langmuir 15:5403-5409.

[49] Bali S, Chen TT, Chaikittisilp W and Jones CW (2013) Oxidative Stability of Amino Polymer-Alumina Hybrid Adsorbents for Carbon Dioxide Capture, Energy Fuels 27:1547-1554. [50] Turek AM, Wachs IE and DeCanio E (1992) Acidic properties of alumina-supported metal oxide catalysts: an infrared spectroscopy study, J Phys Chem 96:5000-5007. [51] Aravind PR, Mukundan P, Pillai PK and Warrier KGK (2006) Mesoporous silica-alumina aerogels with high thermal pore stability through hybrid sol-gel route followed by subcritical drying, Microporous Mesoporous Mater 96:14-20. 
[52] Digne M, Sautet P, Raybaud P, Euzen P and Toulhaut H (2004) Use of DFT to achieve a rational understanding of acid-basic properties of $\gamma$-alumina surfaces, J Catal 226:54-68.

[53] Ravenelle RM, Copeland JR, Van Pelt AH, Crittenden JC and Sievers C (2012) Stability of $\mathrm{Pt} / \gamma-\mathrm{Al}_{2} \mathrm{O}_{3}$ Catalysts in Model Biomass Solutions, Top Catal 55:162-174.

[54] Ravenelle RM, Copeland JR, Kim WG, Crittenden JC and Sievers C (2011) Structural Changes of $\gamma-\mathrm{Al}_{2} \mathrm{O}_{3}$-Supported Catalysts in Hot Liquid Water, ACS Catal 1:552-561.

[55] Koichumanova K, Vikla AKK, de Vlieger DJM, Seshan K, Mojet BL and LeffertsL (2013)

Towards Stable Catalysts for Aqueous Phase Conversion of Ethylene Glycol for Renewable Hydrogen, ChemSusChem 6:1717-1723.

[56] Réocreux R, Jiang T, Iannuzzi M, Michel C and Sautet P (2018) Structuration and Dynamics of Interfacial Liquid Water at Hydrated $\gamma$-Alumina Determined by ab Initio Molecular Simulations: Implications for Nanoparticle Stability, ACS Appl Nano Mater 1:191-199.

[57] Holewinski A, Sakwa-Novak MA and Jones CW (2015) Linking $\mathrm{CO}_{2}$ Sorption Performance to Polymer Morphology in Aminopolymer/Silica Composites through Neutron Scattering, J Am Chem Soc 137:11749-11759. 